\title{
Characteristic of plasma bubbles observed by DMSP in the topside ionosphere during the year 2005
}

\author{
K PATEL and A K Singh* \\ Department of Physics, Banaras Hindu University, Varanasi 221 005, India. \\ *e-mail: abhay_s@rediffmail.com
}

\begin{abstract}
To study the characteristic of plasma bubbles in the topside ionosphere during the solar minima, we have analyzed a large database of post-sunset plasma density measurement acquired during $~ 5104$ equatorial crossings made by Defense Meteorological Satellite Program (DMSP) F14 in 2005. On 675 of these crossings, equatorial plasma bubbles (EPBs) events were observed as intervals of depleted and irregular plasma densities that degrade communication and navigation signals. We have analyzed these EPB events to study their distributions with month, season and longitude. To test for possible dependence of EPB occurrence at topside altitudes on the level of magnetic activity, we compared the distributions of one year database with those of Kp index at the time of equatorial crossings by the DMSP satellites. We also examined the response of the evening sector, low-latitude ionosphere during eight magnetic storms with minimum Dst $\leq-100 \mathrm{nT}$. We observed that EPBs occurred regularly during geomagnetic storms, especially in the initial and main phases but can be suppressed sometimes for days, after prolonged activity during recovery phases. These results are discussed according to the other reported results.
\end{abstract}

\section{Introduction}

Equatorial plasma bubbles (EPBs) are plasma density depletions and accompanying plumes of irregularities that give rise to severe radio signal disruptions (Huang et al 2001; Burke et al 2004a, 2004b). It is generally conceded that EPBs grow in the post-sunset, low latitude ionosphere through a generalized Rayleigh-Taylor instability (Ott 1978). The growth of this instability depends on the development of steep, upward plasma density gradients after sunset in the bottom side F-layer, local electric fields with an eastward component, and low values of the flux integrated Pederson conductivity (Anderson and Haerendel 1979). EPBs are most frequently observed in the pre-midnight sector, as shown in large quantities of in-situ and ground-based data, such as a range spread echo in ionogram (Woodman and Lahoz 1976), radio scintillation shown as rapid amplitude or phase fluctuations for the radio wave communication between space and ground (Basu and Basu 1985), the pronounced density depletion in airglow (Kelley et al 2002; Sahai et al 2004), significant bite-outs in density from in-situ observations (Hysell and Burcham 1998; Huang et al 2002; Burke et al 2004a, 2004b; Su et al 2006), and their signatures in the magnetic field (Stolle et al 2006). Recently, making use of the advantage of ground-based GPS receiver data, occurrence characteristics of plasma bubbles were studied by Nishioka et al (2008).

Periodic plumes of rapidly rising equatorial irregularities detected by radars suggest that gravity waves propagating in the neutral atmosphere act as seeds for EPBs (Kelley et al 1981). McClure et al (1998) argue that the tropospheric disturbances are the main seeds for the EPBs. Later, Prakash (1999) proved by his theoretical model that only gravity wave winds are responsible

Keywords. Ionosphere (equatorial ionosphere, plasma waves and instabilities, ionospheric irregularities); equatorial plasma bubbles. 
for the bubble formation and predicted that the sources for gravity waves are at low latitudes.

It has been reported that plasma bubbles occurrence has various temporal variations, such as solar activity dependence (Sahai et al 2000; Huang et al 2002), seasonal-longitudinal variation (Burke et al 2004b; Makela et al 2004), several days variations and day-to-day variation (Basu et al 1996; Fargundes et al 2005). Strong seasonal versus longitudinal variability characterizes the frequency of EPB occurrence (Aarons 1993; Huang et al 2001; Burke et al 2004a, 2004b). Huang et al (2001) first surveyed EPB activity for solar maximum years 1989 and 1991 during $\sim 1500$ orbits of Defense Meteorological Satellite Program (DMSP) satellites at $840 \mathrm{~km}$ in the post-sunset local time sector and found that seasonal versus longitudinal distribution were generally consistent with ground-based measurements (Aarons 1993) and the Scherliess and Fejer (1997) storm time model. Huang et al (2001) also noted that the number of EPBs increases in the main phase of geomagnetic storms but was suppressed during the recovery phase. Further Huang et al (2002) extended their study to include multiple DMSP spacecraft over a full solar cycle 1989-2000 and suggested that penetration electric fields drive many storm time EPBs. Burke et al (2003) compared the DMSP EPB observations with co-ordinated ground measurements from Jicamarca unattended long-term studies of the ionosphere and atmosphere (JULIA) radar and a scintillation monitor in Ancon, Peru $\left(\mathrm{ML}\right.$ at $\left.0.9^{\circ} \mathrm{N}\right)$ and determined that overall trends in seasonal averages of EPB occurrence correlated closely despite differences in the actual rates since many ionospheric disturbances that causes measurable $S_{4}$ scintillations do not reach DMSP altitudes $(\sim 840 \mathrm{~km})$.

Burke et al (2004a) found that DMSP EPB rates were well correlated with plasma density measurements for March-April 2000 and 2002 from the Republic of China Satellite (ROCSAT-1) in a $35^{\circ}$ inclination orbit at $650 \mathrm{~km}$ when the spacecraft crossed the same longitude sector within \pm 15 min. Burke et al (2004a) also examined scintillation measurements from a network of GPS receivers in South America and proposed that energetic electron precipitation from the inner radiation belt affects the global distribution of EPBs and the climatology of radio wave scintillations. The EPB climatology were further updated by Gentile et al (2006) with more database of DMSP and examined variations in $\mathrm{EPB}$ rates during different phases of the solar cycle.

Earlier studies of the effects of geomagnetic storms on the development or inhibition of ionospheric irregularities have shown that there is a general consequence that magnetic activity tends to suppress the generations of spread-F or plasma bubbles in the pre-midnight period, whereas the possibility of observing spread-F or plasma bubbles during the post-midnight period increase with magnetic activity (Burke 1979; DasGupta et al 1985; Aarons 1991). Kelley and Maruyama (1992) suggested that enhanced penetration of storm time electric fields to low magnetic latitudes is responsible for the rising post-midnight ionosphere and consequent EPB activity in that local time sector. The model of Scherliess and Fejer (1997) and Fejer and Scherliess (1997) predict that in the early stages of magnetic storms penetrating electric fields cause the post-sunset ionosphere to rise; in the recovery phase a reverse-polarity dynamo causes the post-midnight ionosphere to rise. Huang et al (2001) have shown that EPB activity in the evening sector is enhanced during the early stages of high geomagnetic activity but can be suppressed, sometimes for days, after prolonged elevated activity. Based on the Dynamics Explorer (DE) 2 satellite observations from August 1981 to February 1983, Palmroth et al (2000) investigated the occurrence of EPBs and found that magnetic activity appears to suppress the generation of evening side plasma bubbles with a delay of $2-5 \mathrm{~h}$. Recently, Li et al (2009) studied the dependence of EPB occurrence in the evening side ionosphere, with magnetic activity based on the TEC observations gathered by ground-based GPS receivers located in East Asia and found that the magnetic activity appears to suppress the generation of EPBs with a time delay of more than $3 \mathrm{~h}(4-9 \mathrm{~h})$.

It is interesting to study about the EPBs because plasma density depletions generate rapid changes in both amplitude and phase of radio signals, which moves through the bubbles producing irregularities in the ionosphere. As a result it degrades the communication and navigation signals seriously.

The purpose of this paper is to report on the distribution of EPBs observed by DMSP satellite in the evening sector during the solar moderate/ minimum year 2005. Section 2 briefly describes instrumentation of DMSP satellites mainly spacecraft F14. Section 3 presents the data selection and analysis. The statistical properties of EPB detected by our study are presented in section 4 . We also examined the response of the evening sector low latitude ionosphere during eight magnetic storms with minimum Dst $\leq-100 \mathrm{nT}$ during the year 2005. Section 5 contains the discussion of the results obtained and finally, section 6 summarizes the results.

\section{Instrumentation of DMSP satellites}

DMSP satellites are three-axis stabilized spacecraft that fly in circular, sun-synchronous polar orbits 
Table 1. DMSP EPBs of the year 2005, number of orbits, number of orbits with EPBs and EPBs classified by the depth of deepest depletion $\Delta N$ with respect to the nearby undisturbed plasma density.

\begin{tabular}{lcccc}
\hline Months (2005) & Orbits & EPBs & M-0 & M-1 \\
\hline January & 420 & 42 & - & 42 \\
February & 389 & 54 & 1 & 53 \\
March & 436 & 90 & 54 & 36 \\
April & 421 & 77 & 62 & 15 \\
May & 436 & 45 & - & 45 \\
June & 423 & 49 & - & 49 \\
July & 435 & 34 & - & 34 \\
August & 437 & 23 & - & 23 \\
September & 423 & 103 & 85 & 18 \\
October & 437 & 93 & 81 & 12 \\
November & 423 & 24 & - & 24 \\
December & 424 & 41 & 1 & 40 \\
Total & 5104 & 675 & 284 & 391 \\
\hline
\end{tabular}

with inclination $98.7^{\circ}$ at an altitude of $\sim 840 \mathrm{~km}$. The geographic local times of the orbits are either near the 1800-0600 (F8, F13) or 2100-0900 (F9, F10, F11, F12, F13, F14, F15) local time meridians. Each satellite carries a suite of sensors called the Special Sensors - Ions, Electrons and Scintillations (SSIES) to measure the density temperatures and drift motions of ionospheric ions and electrons. SSIES consist of a spherical Langmuir probe mounted on $0.8 \mathrm{~m}$ booms to measure the densities and temperatures of ambient electrons with three separate sensors mounted on a conducting plate facing in the ram direction (Rich and Hairston 1994; Burke et al 2004a, 2004b). These are ion traps to measure the total ion density, an ion drift meter to measure horizontal $\left(V_{H}\right)$ and vertical $\left(V_{V}\right)$ cross-track components of plasma drifts and a retarding potential analyzer to measure ion temperature and in-track components of plasma drift $V_{\|}$.

\section{Data selection and analysis}

Till now several workers have studied the EPBs after analyzing, the DMSP data up to year 2004 (Huang et al 2001; Burke et al 2004a, 2004b; Gentile et al 2006). Thus for the present study we have selected the relatively solar minimum year of 2005. We have chosen the spacecraft, F14 data of DMSP for our present EPBs study. It crosses the magnetic equator in the evening sector (1900-2200 LT).

To determine when either DMSP satellite encountered an EPB, we examined the distribution of plasma densities measured in the evening sector
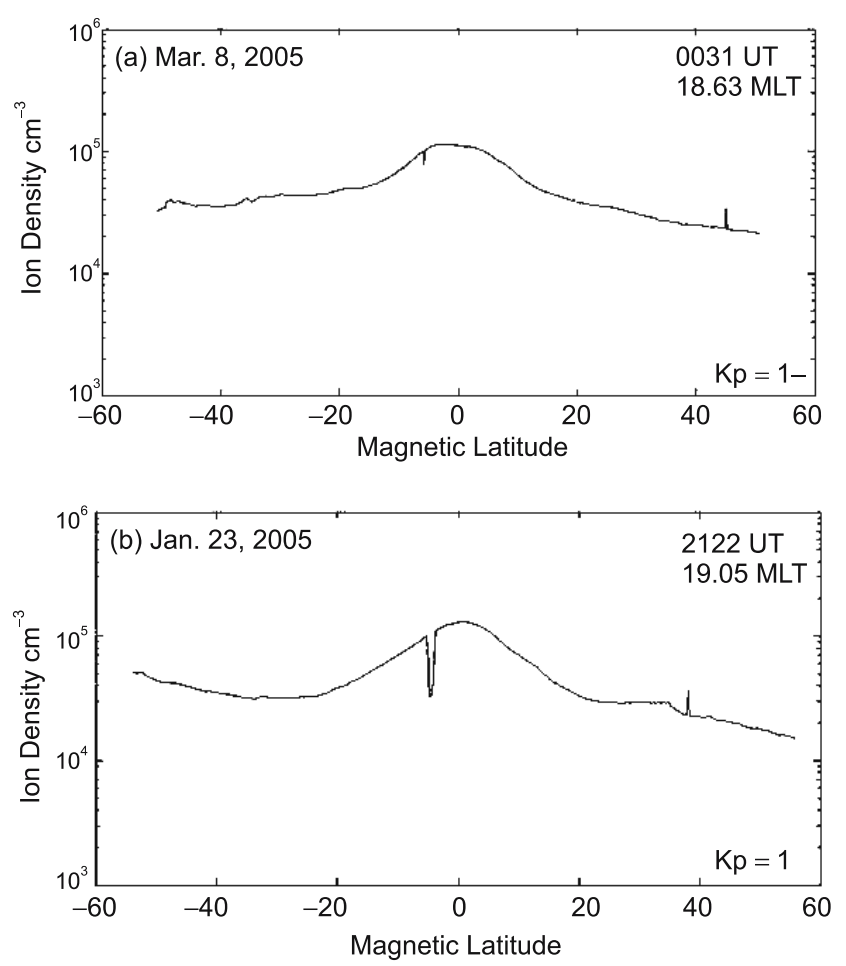

Figure 1. Examples of two categories of bubbles (M-0, M-1) according to the depth of the deepest depletions $\Delta \mathrm{N}$ with respect to nearest undisturbed plasma density. Plasma density categories: (a) M-0 if $\Delta \mathrm{N} \leq 2$, and (b) M-1 if $2<\Delta \mathrm{N} \leq 10$.

and plotted as a function of magnetic latitude. Following the criteria of Huang et al (2001), we have divided bubble encounters into four categories (M-0 to M-3) according to the depth of depletions $\Delta \mathrm{N}$ with respect to the nearby undisturbed plasma density $\mathrm{N}_{0}$ as M-0 if $\Delta \mathrm{N} \leq 2, \mathrm{M}-1$ if $2<\Delta \mathrm{N} \leq 10$, $\mathrm{M}-2$ if $10<\Delta \mathrm{N} \leq 100$ and $\mathrm{M}-3$ if $\Delta \mathrm{N}>100$. If the satellite crossed multiple bubbles during a single orbit, the orbit was regarded as a single encounter and categorized by the depth of the deepest density depletion. A summary of plasma bubbles encounters by DMSP F14 in 2005 according to the M-0 to M-3 categories is listed in table 1 . The statistical description in table 1 predicts that the EPBs under the M-1 category have occurred more than under M-0 category. It was also observed that no EPBs were found in the M-2 and M-3 category in the year 2005. Figure 1(a, b) shows the typical example of the M-0 and M-1 category of the EPBs observed in 2005. Orbital period of DMSP satellites of $\sim 104 \mathrm{~min}$ allow an average of 14 orbits per day. Between orbital ascending nodes, DMSP satellite regress $\sim 25^{\circ}$ in longitude. The DMSP data were divided into 24 longitude bins, each of $15^{\circ}$ wide. During the course of a month a DMSP satellite revisits each longitude sector $\sim 18$ times. The EPB occurrence rates were calculated as the ratio of the number of orbits in which at least one EPB 


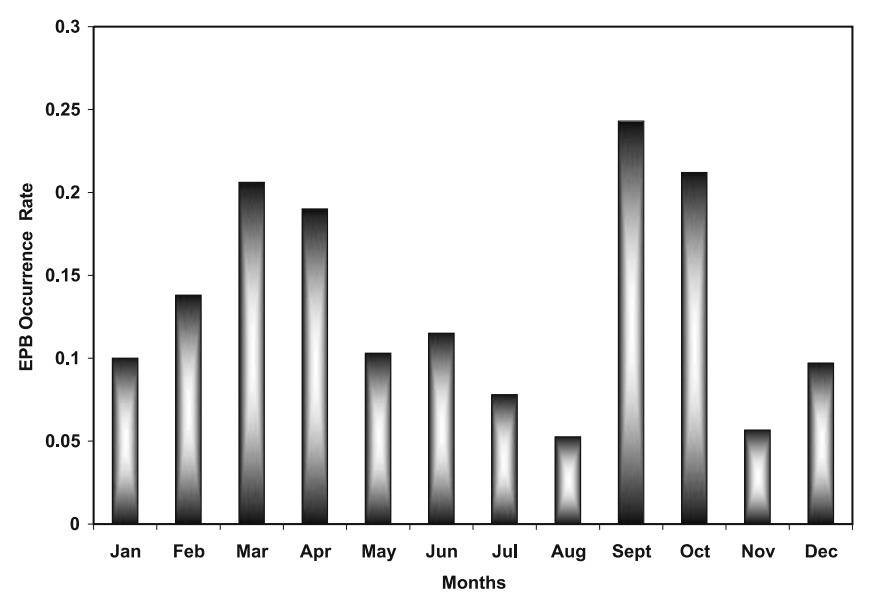

Figure 2. Monthly distribution of EPB encounters by DMSP satellites F14 in 2005. Data are presented as occurrence rate of total equatorial crossings during a given month.

was detected and divided by the total number of orbits for each month (Gentile et al 2006).

\section{Observations and results}

\subsection{General distributions of EPBs}

The distribution of EPB encounters, i.e., occurrence rate of EPB according to month is shown in figure 2. The figure shows that the EPB occurrence rate is maximum in the equinox month (March, April, September, October) with the peak value of about $\sim 0.24$. The winter months (January, February, November, December) show higher rate of DMSP spacecraft F14 to cross the EPBs $(\sim 0.14)$ than the summer months $(\sim 0.12)$.

To study the seasonal and longitudinal distribution of EPBs, the DMSP data were divided into 24 longitude bins each of $15^{\circ}$. Table 2 gives the total number of DMSP EPBs and orbits per month in each longitude sector for the spacecraft F14 in the year 2005. Figure 3 displays a colour contour plot of EPB occurrence rate on a month versus longitude grid with longitude ranging from $0^{\circ}$ to $360^{\circ}$ in 24 bins of $15^{\circ}$ measured by DMSP satellite for the year 2005. Colours represent the EPBs rates as indicated by the colour bars. For descriptive convenience we divide the globe into five longitude sectors that roughly correspond to the widths of the African and American continents and the Indian, Pacific and Atlantic Oceans (Huang et al 2001). Both seasonal and longitudinal effects are evident with the highest EPB rates during March-April and August-October in the American-Atlantic region. The lowest rates of EPB detection occurred in the Indian-Pacific sectors. Only few localized hot spots appear in the IndianPacific sector. The ionospheric conditions during solar minimum may limit the number of EPBs that reach DMSP altitudes at the appropriate local times (Gentile et al 2006).

To further explain this discrepancy in longitudinal distribution of EPBs occurrence, figure 4 displays Earth's equatorial magnetic field strength, $B_{\text {eq }}$ at DMSP altitude (top panel) and EPB occurrence rates (bottom panel) as a function of geographic longitudes. The values of $B_{\text {eq }}$ are obtained from International Geomagnetic Reference Field Model (IGRF) at an altitude of $840 \mathrm{~km}$ (Burke et al 2004a, 2004b). The bottom panel represents peak and average occurrence of EPB occurrence rates, which show the expected general trend with a maximum occurrence in the Atlantic longitude sector and minimum in the Indian. After comparing upper and bottom plots we observe that the EPBs are most likely to develop at longitudes where $B_{\text {eq }}$ is weakest (Huang et al 2001; Burke et al $2004 a, 2004 b)$. Both the above figures show that the relatively large equatorial magnetic field in the Indian-Pacific sector reduces the $\mathrm{R}-\mathrm{T}$ growth rate thus rendering the nonlinear manifestation of EPBs at $840 \mathrm{~km}$ less likely (Huang et al 2001), which explains the relatively low DMSP EPBs occurrence rate in India-Africa-Pacific region during 2005.

\subsection{Effect of geomagnetic activity}

To understand the dependency of EPB occurrence on the geomagnetic activity, we compare the distributions of EPBs with Kp index at the times of equatorial crossings by the DMSP satellite. The 3-hourly Kp index quantifies the disturbance produced in the horizontal component of the Earth's magnetic field in the range of 0-9. Distribution of $\mathrm{EPB}$ encounters as a function of Kp-index is shown in figure 5. The solid line strip shows the Kp distribution for total DMSP orbits by F14 in 2005 whereas dashed strip depicts the Kp distributions for the orbits in which EPBs were observed. Both the plots have peak values when $\mathrm{Kp}=2$. Although we see that the total sample and EPB encounter plots decrease for $\mathrm{Kp}>2$, the rates of decrease differ.

To examine the response of major geomagnetic storms on EPBs occurrence, we have selected total of eight strong magnetic storms with Dst $\leq$ $-100 \mathrm{nT}$ occurred in the year 2005 . Table 3 shows the dates, the approximate universal times and values of minimum Dst index. Figure 6 shows plots of Dst index of four large magnetic storms that occurred in the year 2005. Superposed on each of the plots are vertical lines coincident in time with EPB encounters by F14 in 2005. The depletion category M-0 is represented by blue lines and M-1 by red lines. The local times of occurrence of M-0 and M-1 type of bubbles are also marked. 


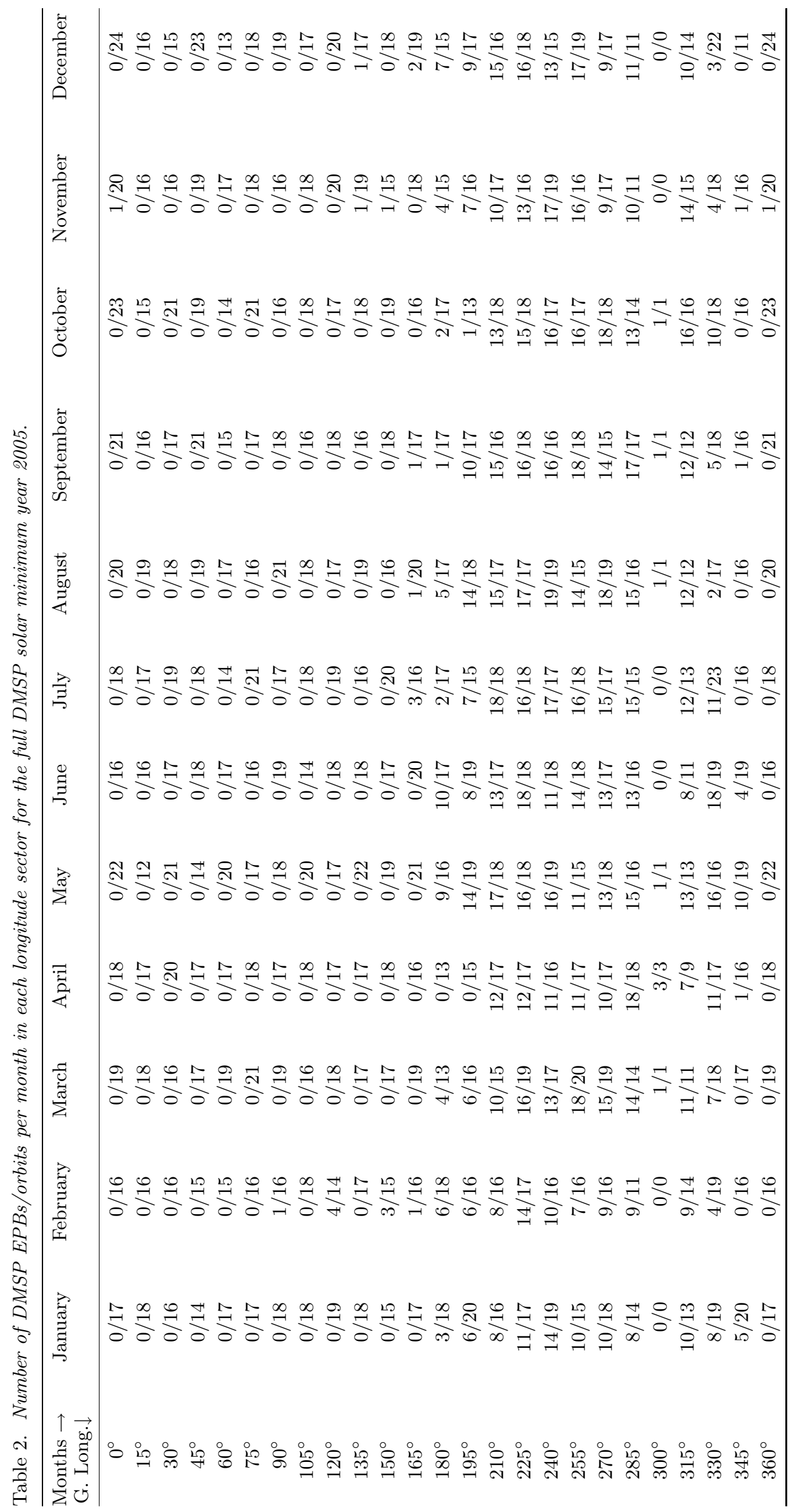




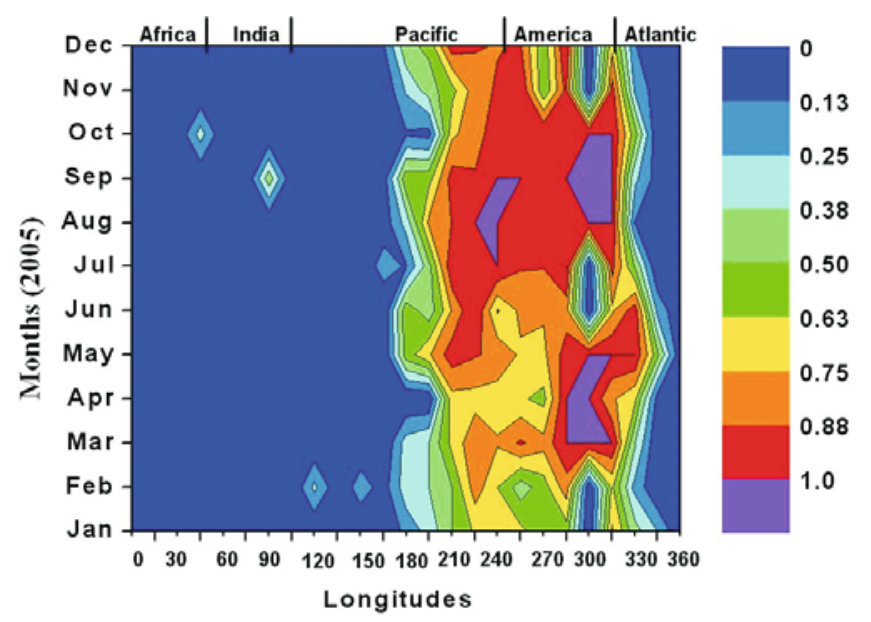

Figure 3. Contour plot of EPB rates for solar minimum year 2005 .
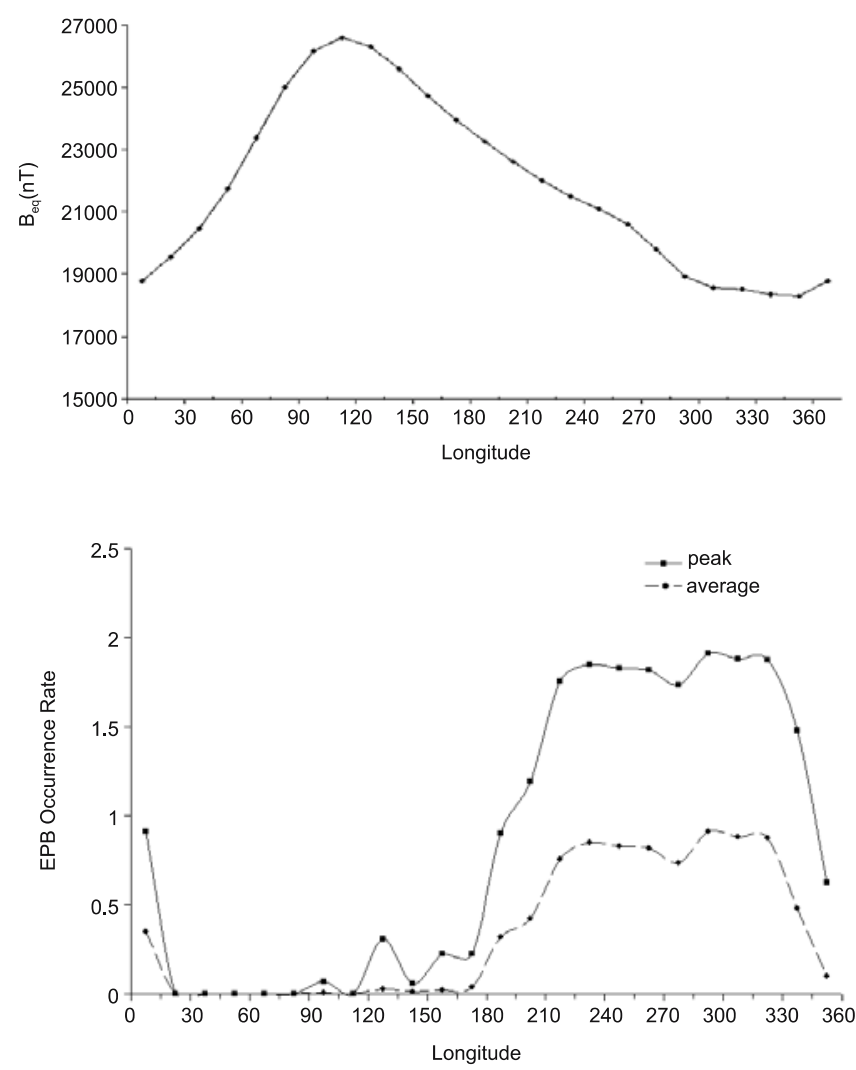

Figure 4. IGRF values of Earth's magnetic field strength $B_{\text {eq }}$ (top panel) and maximum $(\% \max )$ and average $(\langle \%\rangle)$ EPB occurrence rates (bottom panel). Solid and dashed lines represent values of $\% \max$ and $(\langle \%\rangle)$, respectively.

Figure 6(a) shows the geomagnetic storm whose main phase started on 7 May at 2100 UT. The storm attains its peak value at $1900 \mathrm{UT}$ on 8 May with Dst value of $-127 \mathrm{nT}$. Both types of plasma bubble M-0 at $1940 \mathrm{LT}$ and M-1 at $2040 \mathrm{LT}$ were observed by DMSP on 8 May during the main phase of the storm and there was not any

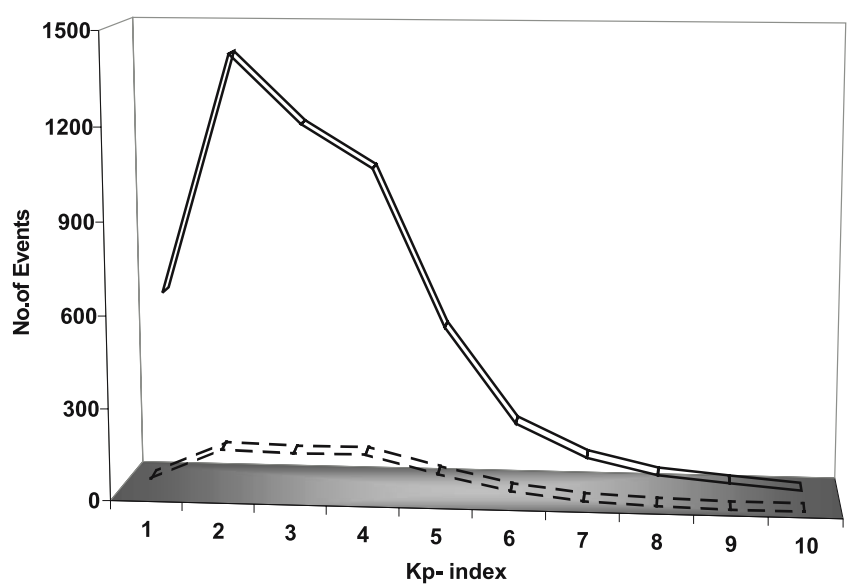

Figure 5. Distributions of EPB encounters as a function of the Kp index. (a) Solid lines plot the number of equatorial crossings while $\mathrm{Kp}$ was in a given range. (b) Dashed lines indicate the number of equatorial crossings when EPBs were detected.

Table 3. Major magnetic storms observed in the year 2005.

\begin{tabular}{lcc}
\hline Storm days & $\begin{array}{c}\text { Peak Dst index } \\
(<-100 \mathrm{nT})\end{array}$ & $\begin{array}{c}\text { Peak time } \\
(\mathrm{UT})\end{array}$ \\
\hline 18 January 05 & $-121 \mathrm{nT}$ & 0900 \\
8 May 05 & $-127 \mathrm{nT}$ & 1900 \\
15 May 05 & $-263 \mathrm{nT}$ & 0900 \\
20 May 05 & $-103 \mathrm{nT}$ & 0900 \\
30 May 05 & $-138 \mathrm{nT}$ & 1400 \\
24 August 05 & $-216 \mathrm{nT}$ & 1200 \\
31 August 05 & $-131 \mathrm{nT}$ & 2000 \\
11 September 05 & $-147 \mathrm{nT}$ & 1100 \\
\hline
\end{tabular}

bubble recorded during recovery phase. Figure 6(b) shows the storm whose main phase started on 29 May at $2300 \mathrm{UT}$ and attains its peak value of Dst index $-138 \mathrm{nT}$ on 30 May at $1400 \mathrm{UT}$ with observations of both types of plasma bubbles at $1914 \mathrm{LT}$ (M-1) and 2010 LT (M-0) during the main phase of storm and suppressing the occurrence in recovery phase. Figure 6(c) shows the two storms with peak value of Dst index $-216 \mathrm{nT}$ and $-131 \mathrm{nT}$ occurred on 24 and 31 August at $1200 \mathrm{UT}$ and $2000 \mathrm{UT}$, respectively. During the first storm both types of plasma bubbles were observed at $1865 \mathrm{LT}$ (M-1) and $1920 \mathrm{LT}$ (M-0) on 24 August during main phase as well as recovery phase on 25 August at 1870 LT (M-1) and 2060 LT (M-0) whereas in second storm plasma bubbles occurred only in main phase at 1940 LT (M-1) and 2000 LT (M-0) suppressing it in recovery phase. Figure 6(d) shows storm with peak Dst index of $-147 \mathrm{nT}$ occurred on 11 September at $1100 \mathrm{UT}$ with occurrence of only M-0 type of plasma bubble at $1945 \mathrm{LT}$. From all of these plots we 


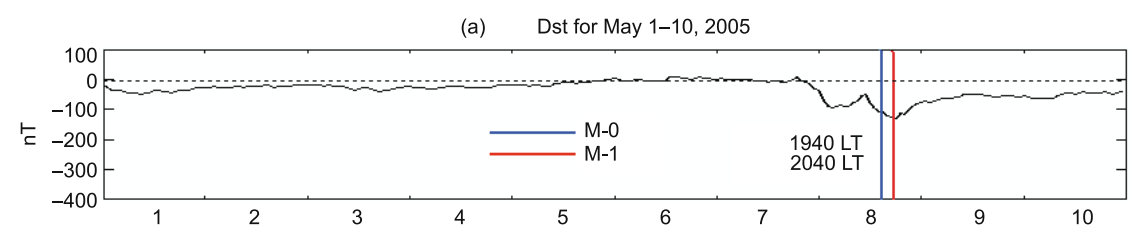

(b) Dst for May 21-31, 2005
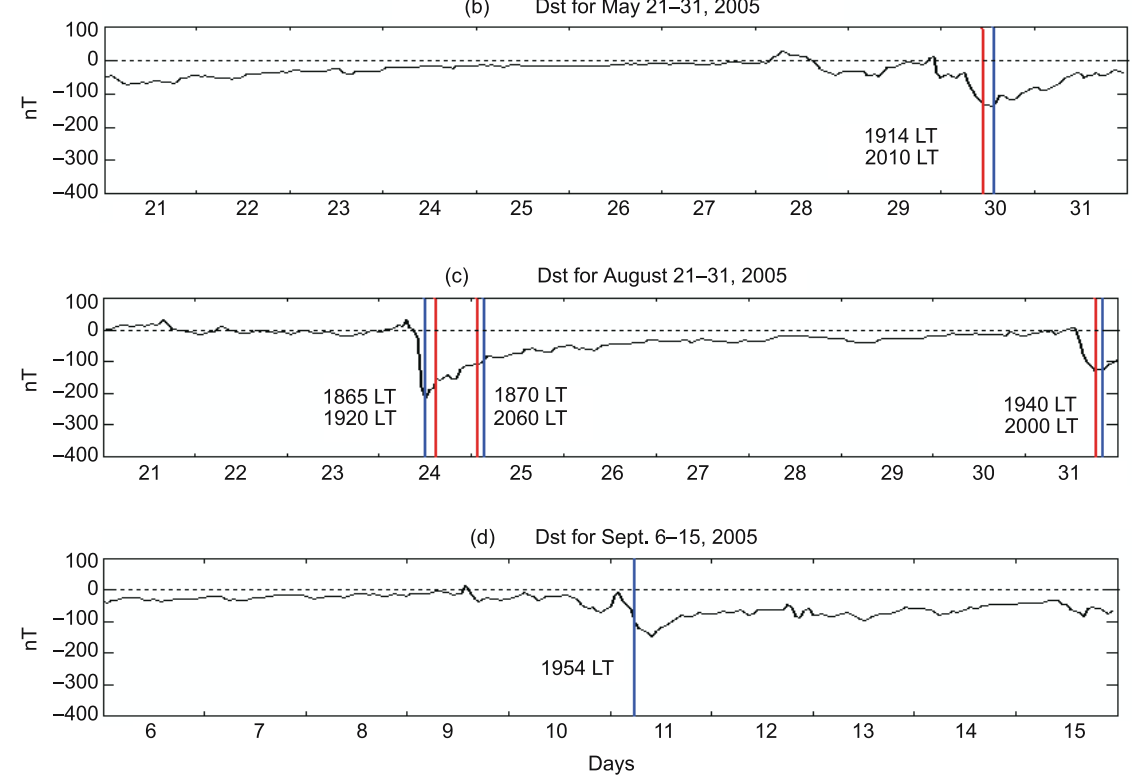

Figure 6. Dst measured near the times of four major magnetic storms in 2005. Each plot gives the data from 11 days roughly centered on the storm's maximum epoch. Vertical lines mark times of DMSP satellite encounters with EPBs. Depletion categories M-0 and M-1 are represented by blue and red colour lines respectively. The local time (LT) of occurrence of both types of plasma bubbles are also marked.

observed that during the early part of each storm, from the sudden storm commencements (SSC) to approximately the peak storm time, intense EPB activity was almost always detected whereas EPB activity was generally suppressed during the recovery phase in the evening sector. During the main phase of storm the penetration electric field enhanced the field associated with the atmospheric dynamo in the post-sunset sector (Haerendel and Eccles 1992), facilitating the triggering of the R-T instability.

\section{Discussion}

In this paper, we have presented DMSP observations of EPB encounters in the evening topside ionosphere during the year 2005. Our results show seasonal and longitudinal variation in agreement with those of past studies which employed ground and satellite-based measurements (Basu and Basu 1985; Aarons 1993; Kil and Heelis 1998; Burke et al 2000; Huang et al 2001; Burke et al 2004a, 2004b; Gentile et al 2006; Li et al 2009).

The typical categories of the DMSP observed EPBs during 2005 falls mainly under M-0 and M-1.
Huang et al (2001) have also reported the maximum occurrence of EPBs were of M-0 and M-1 categories during the year 1981 and 1991. The monthly occurrence rate of EPBs shows the maximum occurrence in equinoctial months (March, April, September and October) than the other months of 2005. Huang et al (2001) also obtained maximum rate of EPB occurrence in the equinox, least in the summer and moderate in winter. Similar seasonal trends of EPBs were also reported by ground-based scintillation observations (Aarons 1993). The colour contour plot of EPB occurrence rate on a month versus longitude shows both seasonal and longitudinal effects with the highest EPB rates during equinox months in the AmericanAtlantic region and only a few isolated areas in the India-Africa-Pacific region. Burke et al (2004a) suggested that there are two geographical features capable of influencing more EPB formation occur at South American longitudes, the Andes Mountain and South Atlantic Anomaly. McClure et al (1998) suggested that wind turbulence above the Andes generates upward propagating gravity waves that seed bottom side density perturbations that grow into EPBs. The relatively large equatorial magnetic field in the Indian-Pacific sector reduces 
the $\mathrm{R}-\mathrm{T}$ growth rate thus rendering the nonlinear manifestation of EPBs at $840 \mathrm{~km}$ less likely (Huang et al 2001, Burke et al 2004a), which explains the relatively low DMSP EPBs occurrence rate in India-Africa-Pacific region during 2005. Gentile et al (2006) have also reported DMSP EPB rates generally less than 5\% except in America-AtlanticAfrica sector and a few isolated areas during solar minimum period of 1994-1997. Since each DMSP spacecraft measures plasma density at $\sim 840 \mathrm{~km}$ near a specific LT and equatorial crossings regress in longitude by $25^{\circ}$ from one orbital to the next, a DMSP satellite may miss many EPBs especially during solar minimum period (Gentile et al 2006). This may be the reason of relatively low DMSP EPB occurrence rate in India-Africa-Pacific region during 2005. However, DMSP satellites do observe internal irregularities within depletions with longer lifetimes of several years. While satellites such as Atmospheric Explorer E and ROCSAT-1 flying in the low inclination orbits sample plasma density irregularities at all longitudes and LTs but their operational lifetimes were limited to few years (Burke et al 2004a; Gentile et al 2006).

Huang et al (2001) depending on the R-T growth rate suggested that the difference in the occurrence rate of EPB, gives the difference in the strength of the equatorial magnetic field in the different regions. We observe inverse correlation of average and peak values of EPB occurrence with that of local magnetic field $B_{\text {eq }}$. Similar inverse relationship between $B_{\text {eq }}$ and EPB occurrence rates were also reported by Huang et al (2001) and Burke et al (2004a, 2004b). This may be due to the effect of the ring current that develops a magnetic field around the Earth which is in opposite relation to that of Earth's magnetic field. So, wherever Earth's magnetic field becomes higher the difference between the solar protons and electrons becomes weaker (Huang et al 2001). The effect of geomagnetic storm on occurrence of EPBs is shown in figure 6, which shows that the EPBs develop in the evening sector during the early stages of high magnetic activity periods and are later suppressed. During the main phase of the penetration, electric field enhanced the field associated with the atmospheric dynamo in the post-sunset sector, facilitating the triggering of $\mathrm{R}-\mathrm{T}$ instability (Burke et al 2000). The Dst index responds to the changes in both the magnetopause current and the ring current (Mayaud 1980). During rapid changes in the solar wind pressure, the magnetic field in the inner magnetosphere increases or decreases. As a result, the inductive electric field rises affecting the whole magnetosphere-ionosphere system. We know that the negative values of the Dst index signifies the intense storm, i.e., the ring current is either moving closer to the Earth or the ring current is growing. Both actions require the presence of intense electric fields in the magnetosphere. The ring current can move closer to the Earth only if the magnetospheric electric field has penetrated closer to the Earth than the initial ring current location. Due to such penetration of magnetospheric electric field the stability of equatorial ionosphere is affected in the evening sector, which triggers the EPB occurrence (Huang et al 2001). Thus the enhancement and suppression of pre-midnight equatorial spread-F depends on the relative contributions from the prompt penetration and ionospheric disturbance dynamo induced electric field disturbances with respect to local time effects during the geomagnetic storms (Martinis et al 2005; Basu et al 2007).

Although there have been some apparent conflicts when we compare our DMSP results with other derived ground-based measurements, there are several cases which confirms the DMSP measurements of EPBs. The initial study by Huang et al (2001) found good agreement with groundbased measurements by Aarons (1993). Burke et al (2003) compared DMSP observation with UHF scintillations at Ancon and showed that when $S_{4}>0.8$, EPB detection by DMSP and UHF scintillation followed the same pattern. Recently, Wiens et al (2006) found excellent agreement between GPS scintillation data from Asmora and DMSP EPB rates for the longitude sector of East Africa at 2130 MLT. Thus, we observe that DMSP measurements provide a sound basis for EPBs analysis.

\section{Conclusion}

We have analyzed complete one year (2005) of EPBs observations made with DMSP F14 plasma density profiles. Out of the total crossings of $\sim 5104$ we have obtained 675 crossings with EPBs during the year 2005. The month versus longitude plot shows both seasonal and longitudinal effects with highest EPB rate during equinox months in the American-Atlantic region and a few isolated areas in the Indian-Africa region. We also observe that largest plasma depletions occurred during the main phases of the geomagnetic storms at the time of peak occurrence whereas the recovery phase of the storm is marked by absence of bubbles. The observed inverse correlation of average and peak values of EPB occurrence with that of local magnetic field may be due to the ring current that develops the magnetic field around the Earth which is inversely related with Earth's magnetic field. Our above characteristics of EPBs are in agreement with those of past studies of ground and/or satellite based measurements. 


\section{Acknowledgement}

The work is partly supported by DST, New Delhi under SERC project and partly by UGC, New Delhi under Major Research Project.

\section{References}

Aarons J 1991 The role of the ring current in the generation or inhibition of equatorial $F$ layer irregularities during magnetic storms; Radio Sci. 26 1131.

Aarons J 1993 The longitudinal morphology of equatorial F layer irregularities relevant to their occurrence; Space Sci. Rev. 63209.

Anderson D N and Haerendel G 1979 The motion of depleted plasma regions in the equatorial ionosphere; J. Geophys. Res. 844251.

Basu S and Basu S 1985 Equatorial scintillations: Advances since ISEA-6; J. Atmos. Terr. Phys. 47 753-768.

Basu S, Kudeki E, Basu Su, Valladares C E, Weber E J, Zengingonul $\mathrm{H} \mathrm{P}$, Bhattacharyya $\mathrm{S}$, Sheehan R, Meriwether J W, Biondi M A, Kuenzler $\mathrm{H}$ and Espinoza J 1996 Scintillations, plasma drift, and neutral winds in the equatorial ionosphere after sunset; J. Geophys. Res. 101(A12) 26,795-26,809.

Basu S, Basu Su, Rich F J, Groves K M, Mackenzie E, Coker C, Sahai Y, Fagundes P R and Becker-Gedes F 2007 Response to the equatorial ionosphere at dusk to penetration electric fields during intense magnetic storms; J. Geophys. Res. 112 A08308 doi: 10.1029/ 2006JA012192.

Burke W J 1979 Plasma bubbles near the dawn terminator in the topside ionosphere; Planet. Space Sci. $\mathbf{2 7}$ 1187.

Burke W J, Rubin A G, Maynard N C, Gentile L C, Sultan P J, Rich F J, Beaujardiere O de La, Huang C Y and Wilson G R 2000 Ionospheric disturbances observed by DMSP at middle to low latitudes during the magnetic storm of June 4-6, 1991; J. Geophys. Res. 105 $18,391$.

Burke W J, Huang C Y, Valladares C E, Machuzak J S, Gentile L C and Sultan P J 2003 Multipoint observations of equatorial plasma bubbles; J. Geophys. Res. 108(A5) 1221 doi: 10.1029/2002JA009382.

Burke W J, Gentile L C, Huang C Y, Valladares C E and Su S Y 2004a Longitudinal variability of equatorial plasma bubbles observed by DMSP and ROCSAT-1; J. Geophys. Res. 109 A12301 doi: 10.1029/ 2004JA010583.

Burke W J, Huang C Y, Gentile L C and Bauer L 2004b Seasonal-longtudinal variability of equatorial plasma bubbles; Ann. Geophys. 22 3089-3098.

DasGupta A, Maitra A and Das S K 1985 Post-midnight equatorial scintillation activity in relation to geomagnetic disturbances; J. Atmos. Terr. Phys. 47911.

Fejer B G and Scherliess L 1997 Empirical models of storm time equatorial zonal electric fields; J. Geophys. Res. 102 $24,047-24,056$

Fagundes P R, Pillat V G, Bolzman M J A, Becker-Guedes F, Abalde J R and Aranha S L 2005 Observations of $\mathrm{F}$ layer electron density profiles modulated by planertary wave type oscillations in the equatorial ionospheric anomaly region; J. Geophys. Res. 110 A12302, doi: 10.1029/2005JA011115.
Gentile L C, Burke W J and Rich F J 2006 A global climatology for equatorial plasma bubbles in the topside ionosphere; Ann. Geophys. 24163.

Haerendel G and Eccles J V 1992 The role of the equatorial electrojet in the evening ionosphere; J. Geophys. Res. 97 1181.

Huang C Y, Burke W J, Machuzak J S, Gentile L C and Sultan P J 2001 DMSP observations of equatorial plasma bubbles in the topside ionosphere near solar maximum; J. Geophys. Res. 106 8131-8142.

Huang C Y, Burke W J, Machuzak J S, Gentile L C and Sultan P J 2002 Equatorial plasma bubbles observed by DMSP satellites during a full solar cycle: Toward a global climatology; J. Geophys. Res. 107(A12) 1434 doi: 1029/2002JA009452.

Hysell D L and Burcham J D 1998 JULIA radar studies of equatorial spread F; J. Geophys. Res. 103 29,155-29,167.

Kelley M C and Maruyama T 1992 Diagnostic model for equatorial spread F-2, The effect of geomagnetic activity; J. Geophys. Res. 971271.

Kelley M C, Larsen M F, Lahoz C and McClure J P 1981 Gravity wave initiation of equatorial spread F: A case study; J. Geophys. Res. 869087.

Kelley M C, Makela J J, Ledvina B M and Kintner P M 2002 Observations of equatorial spread-F from Haleakala Hawaii; Geophys. Res. Lett. 29(20) 2003 doi: 10.1029/2002GL015509.

Kil H and Heelis R A 1998 Global distribution of density irregularities in the equatorial ionosphere; J. Geophys. Res. 103407.

Li G, Ning B, Liu L, Wan W and Liu J Y 2009 Effect of magnetic activity on plasma bubbles over equatorial low-latitude regions in East Asia; Ann. Geophys. 27 303-312.

Makela J J, Ledvina B M, Kelley M C and Kinter P M 2004 Analysis of the seasonal variations of equatorial plasma bubbles occurrence observed from Haleakal, Hawaii; Ann. Geophys. 22 3109-3121.

Martinis C R, Mendillo J M and Aarons J 2005 Toward a synthesis of equatorial spread $\mathrm{F}$ onset and suppression during geomagnetic storms; J. Geophys. Res. 110 A07306 doi: 10.1029/2003JA010362.

Mayaud P N 1980 Derivation, meaning, and use of geomagnetic indices; Geophys. Monogr. Ser. 22 115-129 AGU Washington D C.

McClure J P, Singh S, Bamgboye D K, Johnson F S and Kil H 1998 Occurrence of equatorial $\mathrm{F}$ region irregularities: Evidence for tropospheric seeding; J. Geophys. Res. 103 29119.

Nishioka M, Saito A and Tsugawa T 2008 Occurrence characteristics of plasma bubble derived from global groundbased GPS receiver networks; J. Geophys. Res. 113 A05301 doi: 10.1029/2007JA012605.

Ott E 1978 Theory of Rayleigh-Taylor bubbles in the equatorial ionosphere; J. Geophys. Res. 832066.

Palmroth M, Laakso H, Fejer B G and Pfaff Jr R F 2000 DE2 observations of morningside and eveningside plasma density depletions in the equatorial ionosphere; J. Geophys. Res. 105(A8) 18,429-18,442.

Prakash S 1999 Production of electric field perturbations by gravity wave winds in the E region suitable for initiating equatorial spread F; J. Geophys. Res. 10410051.

Rich F J and Hairston M 1994 Large-scale convection patterns observed by DMSP; J. Geophys. Res. 99 3827-3844.

Sahai Y P, Fagundes P R and Bittencourt J A 2000 Transequatorial $\mathrm{F}$ region ionospheric plasma bubbles: Solar cycle effects; J. Atmos. Sol. Terr. Phys. 62 1377-1383. 
Sahai Y, Fagundes P R, Abalde J R, Pimenta A A, Bittencourt J A, Otuska Y and Rios V H 2004 Generation of large-scale equatorial F-region plasma density depletions during low range spread-F season; Ann. Geophys. 22 15-23.

Scherliess L and Fejer B G 1997 Storm time dependence of equatorial disturbance dynamo zonal electric fields; J. Geophys. Res. 102 24,037-24,046.

Stolle C, Luhr H, Rother M and Balasis G 2006 Magnetic signatures of equatorial spread $\mathrm{F}$ as observed by CHAMP satellite; J. Geophys. Res. 111 A02304 doi: 10.1029/2005JA011184.
$\mathrm{Su} \quad \mathrm{S} \quad \mathrm{Y}, \quad$ Lin $\mathrm{C} \quad \mathrm{H}, \quad \mathrm{Ho} \quad \mathrm{H} \quad \mathrm{H}$ and Chao $\mathrm{C} \quad \mathrm{K}$ 2006 Distribution characteristics of topside ionospheric density irregularities: Equatorial versus midlatitude regions; J. Geophys. Res. 111 A06305 doi: 10.1029/ 2005JA011330.

Weins R H, Ledvina B M, Kintner P M, Afewerki M and Mulugheta Z 2006 Equatorial plasma bubbles in the ionosphere over Eritrea: Occurrence and drift speed; Ann. Geophys. 24 1443-1453.

Woodman R F and Lahoz C 1976 Radar observations of F region equatorial irregularities; J. Geophys. Res. 81 $5447-5466$.

MS received 7 July 2009; revised 12 November 2009; accepted 21 December 2009 